\title{
Litígios potenciais na atividade agropecuária
}

\section{Potential litigation in agricultural and cattle raising activities}

\author{
Zung Che Yee ${ }^{1 *}$; Ricardo Ralisch ${ }^{2}$
}

Resumo

\begin{abstract}
A presente revisão versa sobre as diferentes naturezas de litígios potenciais na atividade agropecuária, e se encontra segmentada por agrupamentos de empregados e empregadores rurais. Discute as ações judiciais ajuizadas tanto na Justiça Trabalhista como Justiça Comum, entendida no âmbito da Justiça Cível, nas esferas estadual ou federal. Visa oferecer contribuições aos profissionais de agronomia, tradicionalmente pouco familiarizados, possibilitando a melhor compreensão de suas ocorrências. Descrevem-se detalhadamente as características de cada uma das ocorrências, bem como as legislações pertinentes, para que possam ser despertadas as discussões e reflexões sobre a problemática, presente no dia a dia. Serão analisados, também, os litígios atingíveis sobre os empreendimentos e nas propriedades rurais, com a ênfase na realização das perícias técnicas, do tipo de profissional que é direcionado, bem como a natureza dos conhecimentos para a sua formação interdisciplinar.
\end{abstract}

Palavras-chave: Litígios rurais, perícias rurais, perícias de engenharia de segurança do trabalho

\begin{abstract}
This review discusses the different nature of potential litigation in agricultural and cattle raising activities, which are segmented into rural workers and rural employers. It analyzes lawsuits pending in the Labor Court, as well as in the Common Pleas Court, within the scope of State and Federal Civil Court rules. The objective of this analysis is to promote a better understanding of these legal problems among professionals in the area of Agronomy, who have, traditionally, little information on them.

A detailed description of the each litigation, as well as of the pertinent legislation, are provided, to give rise to discussions and reflections on these problems, which are part of these professionals' everyday life. Litigation involving companies and rural properties, with emphasis on technical inspections carried out and on the type of professional involved will be analyzed, together with the nature of the knowledge necessary for their interdisciplinary education
\end{abstract}

Key words: Rural litigation, rural investigations, work safety engineering investigations

1 Engenheiro Agrônomo e Engenheiro de Segurança do Trabalho. Mestre e Doutorando em Agronomia pela Universidade Estadual de Londrina. Curitiba, PR. E-mail: zung@netpar.com.br.

2 Professor Doutor, Departamento de Agronomia, Universidade Estadual de Londrina, Londrina, PR. Londrina. PR. E-mail: ralisch@uel.br

* Autor para correspondência. 


\section{Introdução}

O tema aborda os litígios potenciais na atividade agropecuária, abrangendo tanto os empregados como os empregadores rurais. Pretende-se discutir, sob a forma analítica, as ações judiciais, tanto no âmbito da Justiça Trabalhista, como na Justiça Comum, abrangendo as ações que tramitam nas Varas Cíveis Estaduais e Federais. Tem o propósito de contribuir com os profissionais de agronomia, tradicionalmente pouco familiarizados com o tema, possibilitando a melhor compreensão dos litígios presentes e a potencialidade de suas ocorrências.

Serão cotejadas as discussões das ações sobre adicionais de insalubridade e periculosidade, acidentes de trabalho e previdenciárias. Serão comentados, também, alguns tipos de ações de maior ocorrência nas propriedades rurais, tais como: indenizações por deriva de aplicações de herbicidas, lucro cessante decorrente de invasão da área por membros do Movimento Sem Terra (MST), indenização por suspeita de ineficácia de insumos (sementes, fertilizantes, inseticidas), com ou sem liminar de produção antecipada de provas, financiamentos rurais (discussões sobre taxas de juros) e PROAGRO, e litígio decorrente de rompimento de contratos de outras naturezas.

Será abordada a discussão de outros direitos afetos à propriedade, atinentes às seguintes ações: de execuções (ex.: Imposto Territorial Rural - ITR), de desapropriações de reforma agrária e de regularização fundiária, reivindicatórias, possessórias (reintegração, manutenção de posse e interdito proibitório) e de usucapião.

\section{Ações que Envolvem Empregados Rurais na Justiça Trabalhista}

Além das ações que tradicionalmente se litigam sobre os direitos trabalhistas, tais como os valores pecuniários, horas extras, FGTS e de outros direitos, existem as outras ações decorrentes do descumprimento da Segurança e Medicina do
Trabalho, objeto da Lei N.6.514, de 22.12.1977 e alterações posteriores (ATLAS, 2004) onde se aprovaram as Normas Regulamentadoras (NR) e as Normas Regulamentadoras Rurais (NRR), das quais ainda os trabalhadores rurais ainda não estão conscientes dos seus direitos.

As NRs são de aplicação geral e as NRRs são de caráter complementar, no total de cinco, relativas à Segurança e Higiene do Trabalho Rural:

a) NRR-1: Disposições Gerais;

b) NRR-2: Serviço Especializado em Prevenção de Acidentes do Trabalho Rural - SEPATR;

c) NRR-3: Comissão Interna de Prevenção de Acidentes do Trabalho Rural - CIPATR;

d) NRR-4: Equipamentos de Proteção Individual EPI; e

e) NRR-5: Produtos Químicos.

São dois tipos de ações que utilizam as NRs e NRRs de forma simultânea: as referentes a adicional de insalubridade e periculosidade, e as decorrentes de acidente de trabalho.

\section{Adicional de insalubridade e periculosidade na atividade agropecuária}

São consideradas atividades ou operações insalubres as que se desenvolvem acima dos limites de tolerância. Entende-se por limite de tolerância, a concentração ou intensidade máxima ou mínima, relacionada com a natureza e o tempo de exposição ao agente, que não causaria dano à saúde do trabalhador, durante a sua vida laboral.

O exercício de trabalho em condições de insalubridade assegura ao trabalhador a percepção do adicional, incidente sobre o salário mínimo, equivalente a: (a) $40 \%$ para insalubridade de grau máximo; (b) 20\% para insalubridade de grau médio; e (c) $10 \%$ para insalubridade de grau mínimo.

No caso de incidência de mais de um fator de insalubridade, será apenas considerado o de grau mais 
elevado, para efeito de acréscimo salarial, sendo vedada a percepção cumulativa. A eliminação ou neutralização da insalubridade determinará a cessação do pagamento do adicional respectivo.

São consideradas atividades e operações perigosas as que envolvem explosivos e inflamáveis (NR-16 - Anexos 1 e 2). O exercício de trabalho em condições de periculosidade assegura ao trabalhador a percepção do adicional de $30 \%$ incidente sobre o salário, sem os acréscimos resultantes de gratificações, prêmios ou participações nos lucros da empresa.

Sobre a situação de insalubridade e periculosidade na atividade agropecuária divergem das do meio urbano e, para fins ilustrativos, serão mencionados a seguir exemplos práticos para melhor elucidação.

No que tange às atividades insalubres, podem ser citados os operadores de máquinas para destocas (inclusive nos cerrados), tratores, colheitadeiras e automotrizes, maquinário e equipamentos de limpeza, classificação de cereais, secadores etc., que são fontes geradoras de níveis de ruídos acima dos níveis de tolerância segundo as legislações vigentes [NR15 - Anexo $\mathrm{N}^{\mathrm{o}} 1$, com níveis de ruído intermitente ou contínuo, de $85 \mathrm{~dB}$ (decibéis), para a jornada máxima permissível de oito horas].

Outra situação enquadrável seria a Exposição ao Calor (NR-15 - Anexo No 3), que define os limites de tolerância, aplicável para regime de trabalho intermitente com período de descanso no próprio local de prestação de serviço, sendo dimensionado segundo período de trabalho e intervalo de descanso, em conformidade com o tipo de atividade, classificado como: (a) leve; (b) moderada; e (c) pesada, dimensionado segundo a Taxa de Metabolismo, que corresponde o gasto de $\mathrm{kcal} / \mathrm{h}$.

Segundo a inspeção de trabalho realizado no local de trabalho, ainda podem ser encontradas atividades ou operações executadas em locais alagados ou encharcados, com umidade excessiva, capaz de produzir danos à saúde do empregado rural, que poderiam ser consideradas insalubres (NR-15 Anexo 10).

Da mesma forma, os trabalhadores rurais são passíveis de incidência de adicional de insalubridade por agentes químicos, onde a caracterização se dê com base por limites de tolerância (NR-15 - Anexo $\mathrm{N}^{\mathrm{o}}$ 11). São basicamente os trabalhadores que ficam expostos a agentes químicos quando forem ultrapassados os limites de tolerância estabelecidos nas normas legais, podendo ocorrer tanto em empregados rurais como nos que trabalham em armazéns de propriedades agrícolas.

Dentre os princípios que norteiam a incidência do adicional de insalubridade (NR-15 - Anexo No 14), há também os agentes biológicos. Por analogia de que os empregados urbanos devem perceber o adicional de insalubridade de grau máximo, quando em contato com esgotos, os empregados rurais da atividade de suinocultura e/ou os que laboram com atividade orgânica (que utilizam dejetos de avicultura e de animais), estarão expostos aos mesmos agentes biológicos, que dependem apenas da caracterização pela avaliação qualitativa. Da mesma forma, são atingíveis os empregados rurais nas pequenas unidades de industrialização de defumados (de carne, vísceras, sangue etc.), pela possibilidade de que os animais tenham sido portadores de doenças infectocontagiosas, e/ou de seus efeitos decorrentes de resíduos químicos, de alimentos e rações ingeridas ou mesmo de vacinas aplicadas.

Pelas prerrogativas da abrangência que pode ser incluída nas ações ajuizadas, também por analogia, os empregados rurais que possuem suas atividades em área contendo biodigestores (de metano), encontra-se nas iguais condições de risco das operações inflamáveis dos postos de combustíveis, ensejando o percebimento de adicional de periculosidade, dependendo da análise no local específico do trabalho. 
Ações Indenizatórias por Acidente de Trabalho na Atividade Agropecuária

As ações por acidente de trabalho na atividade agropecuária (YEE, 2004) até o advento da Emenda Constitucional 45 de 2004, eram de competência da Justiça Comum, e hoje integra a Justiça do Trabalho. Os litígios fundamentam-se na sua caracterização, através da realização de Perícias Técnica e Médica nas condições do ambiente de trabalho e das naturezas das lesões e se decorrem do empregador, quer urbano ou rural. Dependendo da natureza, as ações podem resultar em indenizações que vão desde o pagamento do último salário até completar a idade de aposentarse até o arbitramento de um valor de indenização, caso a ação vier a ser julgada procedente.

Quanto à natureza das ações indenizatórias por acidentes de trabalho na atividade rural, podem contemplar a título ilustrativo: (a) os ruídos acima dos limites de tolerância nas atividades cotidianas que ocasionaram a perda auditiva, comprometendo a capacidade de obtenção de novos empregos; (b) exposição habitual a produtos químicos utilizados em lavouras que tenham comprometido à saúde; (c) exposição habitual a partículas de poeiras em armazéns agrícolas com comprometimentos das vias respiratórios; (d) acidentes com maquinários agrícolas com amputação de falange, dedos etc.; (e) queda de maquinários com comprometimento de um ou mais membros e até a morte; (f) exposição habitual a ambiente sujeito a explosões (locais próximos ao tanque de abastecimento de combustível, de armazéns de cereais etc.).

\section{Ações que Envolvem Empregados e/ou Empregadores Rurais na Justiça Federal}

Outras modalidades de litígios que podem ocorrer no meio rural, seriam os litígios instalados por parte dos empregados e/ou empregadores rurais contra o Instituto Nacional de Seguro Social - INSS, denominadas ações previdenciárias (YEE, 2005), com dois aspectos distintos: a) Conversão de tempo de aposentadoria quando laborado em atividades das quais, segundo a legislação vigente, é permitida a redução de tempo para a aposentadoria (atividade em condições especiais). Do ponto de vista prático, correspondem às pessoas enquadradas que, através dessas ações especiais, pleiteiam-se a aposentadoria; ou que já estejam aposentados proporcionalmente, almejando através das ações da espécie, serem majorados os valores, se comprovada que a atividade exercida era objeto de redução de tempo para aposentadoria; b) Ações que visam comprovar que a atividade exercida pelo empregado rural ou urbano, a que se deu origem a aposentadoria, possuía condições para auferir adicional de insalubridade ou de periculosidade, o que redundaria em acréscimo de valores na aposentadoria.

Essas ações são ajuizadas na Justiça Federal e, dependendo dos valores envolvidos, podem ser ajuizadas no Juizado Especial Cível ou nas Varas Previdenciárias.

\section{Ações que Ocorrem com as Propriedades Agropecuárias}

As ações que podem envolver as propriedades rurais, seja diretamente aos proprietários, entre o arrendador e arrendatário, ou entre as propriedades vizinhas são de espectro dos mais variados possíveis, dependendo o foco da discussão.

A título ilustrativo, relacionam-se a seguir, alguns exemplos:

a) Indenizações por deriva de aplicações de herbicidas - são ajuizadas pela parte prejudicada que tenha a lavoura afetada contra o suposto aplicador de herbicida - sob as condições normais, é nomeado um perito da área (ex.: engenheiro agrônomo) onde é analisada entre outros fatores: a possibilidade de ocorrência de tais fatos; a compatibilidade quanto ao efeito do herbicida na lavoura prejudicada; o estabelecimento e eventual nexo e causalidade entre a aplicação de herbicida e o decréscimo da produção esperada; nível tecnológico da lavoura na forma 
conduzida; estimativa das perdas decorrentes, além de outras questões pertinentes (YEE, 2002b);

b) Lucro cessante decorrente de invasão da área por membros do MST - geralmente essas ações são ajuizadas contra o Estado da Unidade da Federação, sucedida de emissão de reintegração de posse não cumprida pelo Poder Público, em que se busca, através de perícia de um profissional da área (ex: engenheiro agrônomo), estimar as perdas decorrentes da invasão, ou determinar que a propriedade deixou de gerar lucros em função da permanência dos invasores. Normalmente tais perícias possuem uma conotação ambiental, requerendo do profissional outros conhecimentos correlatos, tais como: o uso de instrumental de georreferenciamento, imagens de satélite; domínio de legislação ambiental, Código Florestal; e havendo envolvimento de pessoa jurídica, um conhecimento contábil e análise de balanços (YEE, 2003a);

c) Ordinária de indenização por ineficácia de insumos (fertilizantes, herbicidas, inseticidas etc.) geralmente é ajuizada contra a empresa vendedora dos insumos, podendo ser arrolado concomitantemente o fabricante do produto. Via de regra, a ação é acompanhada de liminar de produção antecipada de provas, cuja perícia é realizada através de um profissional (ex.: engenheiro agrônomo) no estágio que se encontra a lavoura, para fins de estimar todos os elementos necessários, tais como: forma de condução da lavoura; tecnologia adotada; estimativa de produção, com avaliação quantitativa e qualitativa dos produtos; procedimento de exames fitopatológicos, para fins de possibilitar a avaliação, a título de contraprova das condições de sementes utilizadas (YEE, 2002b), sendo os dois últimos exames, realizados em laboratórios oficiais credenciados;

d) Ações ordinárias que discutem as taxas de juros de financiamentos rurais concedidos através de agentes financeiros, podendo litigar também, sobre o Programa de Garantia da Atividade Agropecuária PROAGRO, que são ajuizadas pelos produtores rurais que não se satisfizeram com as decisões administrativas de indenizações e que recorreram das decisões judiciais (YEE, 1999). Normalmente, as perícias são realizadas no curso do processo, porém, nada impede que possam ser realizadas na fase da liquidação de sentença. Como a questão não se restringe a cálculos aritméticos, mas envolvem a discussão do cumprimento formal da condução do empreendimento, no caso de lavouras a nomeação do perito deve recair em um profissional da área, como contador ou engenheiro agrônomo. No caso da perícia que envolve a interpretação da condução da lavoura, do ponto de vista prático deve ser conduzida à luz das normas regidas pelo Manual de Crédito Rural - MCR, de elaboração do Banco Central do Brasil, dentro de uma visão bancária e não na ótica de assistência técnica e muito menos, do ponto de vista do produtor rural;

e) Litígios decorrentes de rompimento contratuais de outras naturezas - podendo contemplar tanto contratos de arrendamento, meeiro de atividades rurais, bem como atividades silvi-pastoris.

\section{Ações que Envolvem Direitos à Propriedade em Exploração}

De forma semelhante às ações que ocorrem nas propriedades rurais, podem ser mencionadas as ações afetas às propriedades em exploração, que são inúmeras. A título ilustrativo, menciona-se a seguir alguns tipos, nos quais, via de regra, necessita-se da realização de perícias através de profissionais de qualificações específicas (ex.: engenheiros agrônomos):

a) Ações de execução - são medidas judiciais contra a cobrança de impostos e taxas de naturezas diversas, como por exemplo, de Imposto Territorial Rural ITR. Podem ser de períodos em que a propriedade ainda não pertencia ao atual proprietário e/ou de períodos onde a propriedade não mais pertence ao proprietário, quer originária de transmissão, de desapropriação etc. A nomeação de perito, via de regra, requer um profissional da área, com 
conhecimento da sistemática e procedimentos formais atinentes, bem como o domínio das imperfeições porventura existentes. Deve dominar sobre as características intrínsecas das transmissões de propriedades, de parcelamento de solos etc.

b) Desapropriação de reforma agrária e de regularização fundiária - a natureza das ações de desapropriações para reforma agrária pode desdobrar-se em ações distintas. A primeira, na fase anterior à desapropriação propriamente dita, pode contestar a declaração por parte do Instituto Nacional de Colonização e de Reforma Agrária - INCRA, se a propriedade é efetivamente improdutiva. A segunda, já na fase de desapropriação propriamente dita, via de regra, discute sobre os valores atribuídos (YEE, 2002a). O laudo de avaliação para fins da reforma agrária, explicita que deve ser realizado por engenheiro agrônomo conforme a Lei n. 8.629 (NEGRÃO, 2002):

Art. $12 \S 3^{\circ}$. O Laudo de Avaliação será subscrito por Engenheiro Agrônomo com registro de Anotação de Responsabilidade Técnica - ART, respondendo o subscritor, civil, penal e administrativamente, pela superavaliação comprovada ou fraude na identificação das informações. (NEGRÃO, 2002)

Sobre as desapropriações de regularização fundiária, a discussão encontra-se focada na avaliação do imóvel e suas benfeitorias;

a) Ações reivindicatórias - são ações que envolvem a discussão de domínio (títulos de propriedade). Diferentemente do entendimento coloquial, dentro do campo jurídico, uma determinada propriedade pode ser discutida o domínio independentemente da posse, através de ações de denominações distintas. As perícias de ações reivindicatórias, requerem a indicação de profissionais que detém outros conhecimentos que extrapolam a sua formação básica, mesmo porque envolvem conhecimentos jurídicos sobre a legitimidade e legalidade de títulos dominiais e outros documentos correlacionados; b) Ações possessórias - são ações que se discutem o exercício de posse, podendo ser desdobradas em: (a) reintegração de posse; (b) manutenção de posse; (c) interdito proibitório. A reintegração de posse se caracteriza pela perda da posse; a manutenção de posse quando em continuação da posse, embora turbada; e interdito proibitório a eminência de esbulho (YEE, 2003b).

c) Ações de usucapião - são ajuizadas através de posseiros de áreas, que através da ação própria possa ser legitimado o imóvel, através de emissão de um título de propriedade. Podendo ser realizada unicamente em terras particulares, inclusive de áreas contendo título de propriedade. As ações de usucapião têm sido largamente utilizadas pelos empregados rurais, meeiros, comodatários e/ou arrendatários de má-fé, com o propósito de aquisição fraudulenta das áreas de seus empregadores (YEE, 2003b). Dependendo do tamanho da área a ser usucapida, as prescrições aquisitivas podem ser variadas de cinco a vinte anos.

\section{Considerações Finais}

A análise levada a efeito, demonstra aos agrônomos e outros profissionais da área, que nas atividades profissionais por eles desenvolvidas, carece-se de conhecimentos tais que permitam a exploração de outras áreas de conhecimento que, embora se encontrem contidos nas atribuições profissionais conferidas pelo Conselho Federal de Engenharia, Arquitetura e Agronomia - CONFEA, são pouco difundidas no contexto da agronomia, que mantém um foco restrito na produção vegetal.

A natureza das questões abordadas na presente revisão, no seu primeiro plano, focaliza as implicações sobre a segurança e medicina do trabalho dos empregados rurais. Com exceção dos empreendimentos rurais mais visados pelo Ministério do Trabalho, tais como a produção cana-de-açúcar, citros, entre outros de maior valor de agregado econômico, todas as modalidades de sistemas de 
produção agropecuários expõem os empregados rurais a agentes prejudiciais à saúde, que podem reverter em litígios potenciais aos empregadores.

Por outro lado, as atividades desenvolvidas com a utilização de subprodutos das atividades hortigranjeiros e/ou dos dejetos das atividades pecuárias, do ponto de vista de segurança do empregado rural, sofrem as conseqüências dos agentes biológicos altamente nocivos, a exemplo dos empregados urbanos que trabalham com esgotos e lixos domésticos, sem prejuízos às ações indenizatórias por acidentes de trabalho, consistindo um potencial adormecido de litígios, dado ao seu longo período de prescrição.

No que tange aos litígios sob características mais específicas, decorrentes da aquisição de insumos e de sua não-conformidade (dos seus conteúdos com os rótulos, da eficácia, da germinação de sementes, etc.), o desconhecimento dos direitos básicos contribuem para que deixem de ser exercidos os direitos ou que deixem de ser usados para defesa prévia.

A compreensão da natureza dos litígios potenciais na atividade agropecuária deve ser também alcançada pelos profissionais de agronomia, posto que o conhecimento na atualidade é cada vez mais interdisciplinar. É o momento de reflexões mais profundas sobre o assunto, principalmente aos profissionais e seus papéis que desempenham na atividade agropecuária.

\section{Referências}

ATLAS, Manuais de Legislação. Segurança e medicina do trabalho. 55. ed. São Paulo: Atlas, 2004.

NEGRÃO, T. Código de processo civil e legislação processo em vigor. 34. ed. São Paulo: Saraiva, 2002.

YEE, Z. C. Perícia civil - manual prático. Curitiba: Juruá, 1999.

Perícias de engenharia: análise e crítica. Curitiba: Juruá, 2002a.

Perícias rurais \& florestais: aspectos processuais e casos práticos. Curitiba: Juruá, 2002b.

. Perícias indenizatórias \& de desapropriações: aspectos processuais e casos práticos. Curitiba: Juruá, 2003a.

. Perícias possessórias \& de usucapião: aspectos processuais e casos práticos. Curitiba: Juruá, 2003b.

- Perícias Indenizatórias por acidente de trabalho: aspectos processuais e casos práticos. Curitiba: Juruá, 2004.

- Perícias Previdenciárias, Químicas \& de Proagro: aspectos processuais e casos práticos. Curitiba: Juruá, 2005. 